\title{
A novel business model for aggregating the values of electricity storage
}

\author{
Xian He ${ }^{\mathrm{a}, *}$, Erik Delarue ${ }^{\mathrm{b}, \mathrm{c}, 1}$, William D’haeseleer ${ }^{\mathrm{b}}$, Jean-Michel Glachant ${ }^{\mathrm{a}, \mathrm{c}}$ \\ a University of Paris Sud-XI, Groupe Réseau Jean Monnet, 27 av. Lombart, 92260 Fontenay aux Roses, France \\ ${ }^{\mathrm{b}}$ University of Leuven (K.U. Leuven) Energy Institute, TME Branch (Applied Mechanics and Energy Conversion), Celestijnenlaan 300 A, Box 2421, B-3001 Leuven, Belgium \\ ${ }^{\mathrm{c}}$ EUI-Florence School of Regulation, Robert Schuman Centre for Advanced Studies, Via delle Fontanelle 19, I-50014 San Domenico di Fiesole, Italy
}

\section{A R T I C L E I N F O}

\section{Article history:}

Received 20 August 2010

Accepted 14 December 2010

\section{Keywords:}

Electricity storage

Business model

Optimization

\begin{abstract}
A B S T R A C T
Electricity storage is considered as a valuable source of flexibility with applications covering the whole electricity value chain. Most of the existing evaluation methods for electricity storage are conceived for one specific use of the storage, which often leads to the conclusion that the investment on storage does not pay off. However, the value of storage cannot be properly estimated without taking into account the possibility of aggregating the services that storage can offer to different actors. This paper proposes a new business model that allows aggregating multiple revenue streams of electricity storage in a systematic way. The model consists in coordinating a series of auctions in which the right to utilize the storage unit is auctioned upon different time horizons. In the mean time, non-conflicting usage of storage by the actors in these different auctions is ensured. The functioning of the model is demonstrated by a case study. The results show that a storage unit can achieve higher return on investment in the manner proposed in the business model.
\end{abstract}

(c) 2010 Elsevier Ltd. All rights reserved.

\section{Introduction}

Electricity storage technologies can provide multiple services in generation, transmission and distribution, as well as in enduser activities. The function of electricity storage lies in a bidirectional transformation process: first, electricity is transformed into a storable form of energy at certain efficiency, and second, the stored energy is recovered rapidly into electric energy with certain losses in case of need. Therefore, the electricity storage technology is not an electricity generation means in strict sense, but a valuable flexibility resource adjunctive to all the resources in the power system, which can help achieving a higher asset utilization rate and contributing to the reliability of the power system, especially in the scenarios of massive intermittent renewable energy penetration.

Many studies have been undertaken to evaluate the benefits of electricity storage. Some focus on the arbitrage value of electricity storage in the spot market of electricity (Lund et al., 2009; Muche, 2009; Sioshansi et al., 2009; Sioshansi, 2010; Walawalkar et al., 2007). Walawalkar et al. (2007) also estimate the value of electricity storage to provide regulation services in the market environment. Other studies look into the use of electricity storage at transmission or distribution level (EPRI, 2007; EPRI and US

\footnotetext{
* Corresponding author. Tel.: +3314765 27 54; fax: +3314765 3734 .

E-mail address: xian.he@u-psud.fr (X. He).

${ }^{1} \mathrm{E}$. Delarue is a post-doctoral researcher of the Research FoundationFlanders (FWO)
}

Department of Energy, 2003; Sandia National Laboratories, 2005, 2007). The end-user applications are often studied in the scope of distributed energy storage system. The economics of coupling electricity storage to wind farms is investigated in the literatures (Black and Strbac, 2006; Dufo-López et al., 2009; Korpaas et al., 2003; Kapsali and Kaldelli, 2010). An overlap of the two former categories of studies is discussed by Denholm and Sioshansi (2009) and by EPRI and US Department of Energy (2004), which deal with the transmission-related benefits of combining wind and storage. However, by focusing on only one specific application of electricity storage, most of the analyses mentioned above do not show profitability of investment on storage in the current context. As indicated (Electricity Advisory Committee, 2008; Sandia National Laboratories, 2004; Walawalkar and Apt, 2008), in most cases one sole benefit does not allow the cost recovery of storage facilities. These references point out that the combination of services could lead to a better perspective for the development of storage. Indeed, the societal value of storage should be properly recognized and accounted for the cost recovery of the storage facilities. While engineers continue to make effort to decrease the capital cost and to reduce the cycle losses of electricity storage technologies, economists have began to search for ways to increase the revenue of electricity storage, through the aggregation of the benefits of storage.

To date, relatively little work has been carried out towards that aim. In Sandia National Laboratories (2005), the idea of combination of services is set out, together with the principles of combination, being the operational and technical compatibilities. 
EPRI and US Department of Energy (2004) and Walawalkar and Apt (2008) test several combination options for case studies. Although these studies provide valuable insight of combined benefit of storage, they feature several weaknesses. First, the combination options are case-specific and therefore hard to generalize. This would create difficulty to establish general and non-discriminatory regulation on storage. Second, for a certain combination option, the allocation of storage resource for different services is defined beforehand instead of being the result of an optimization. The common approach for such allocation is to designate a certain period of time during which the storage is dedicated only to one service. As a result, the use of storage at a certain time is still exclusive, which implies in fact a "division" of the storage resource for different services along the time. Third, the combination options studied in these analyses might be specific to the electricity landscape in the US, where the integrated actors can quite easily merge several applications of storage that fall in different spheres of activities. However, the viability of some combination options would be questioned in Europe, where the electricity sector is unbundled and deregulated. In Europe, the challenge of aggregating the values of storage is more related to the questions: (1) how the regulated actors and deregulated actors can share the use of one storage unit, and (2) how the decentralized use of storage by different actors can be effectively coordinated. As an answer to these questions, we propose a business model that allows systematically aggregating the values of storage in deregulated electricity sectors.

The new business model distinguishes itself from the existing methods in that it does not predefine the service that the storage is supposed to offer, nor does it reserve the capacities of the storage in advance for a certain service. The model consists in arranging a series of auctions in which the right to utilize the storage unit is auctioned in different time horizons. The aggregation of values of storage is achieved by superposing the utilization profiles of storage resulting from the auctions chain. A nonconflicting usage of the storage unit is ensured by communicating the utilization profiles resulting from the previous auctions to the actors in the next auction, who are required to respect the utilization profiles previously established when elaborating their own strategy on the use of storage.

The paper is structured as follows. Section 2 introduces the concept of the business model. The mathematic formulation of the model is presented in Section 3. In Section 4, we demonstrate the functioning of the model by a case study, together with a discussion of the key results. Section 5 concludes the paper.

\section{Concept of the business model}

The core of the business model lies in organizing a series of auctions to sell the available power and energy capacities of the storage unit among different actors. The auctions are taking place in sequential time horizons. For example, we can first introduce a week-ahead auction, which is followed by a day-ahead auction, after which finally an hour-ahead auction can be carried out. In each auction, the underlying product is the right to utilize the remaining "capacities of storage" 2 during the auctioned period. Different actors will decide upon their strategy to use the storage according to their own objective function, be it maximizing the profit, minimizing the cost, or minimizing the risk, etc. In principle, all actors are asked to keep the energy balance over the auctioned period, which means that the sum of power

\footnotetext{
${ }^{2}$ The notion of "capacities of storage" refers to the charge/discharge capacities (MW) and energy storage capacity (MWh) of an electricity storage unit.
}

injected into the storage should be equal to the sum of the power withdrawn from the storage unit by the end of the auction period (cycle losses included). This energy balance requirement demonstrates the principle that the storage facility is auctioned as a flexibility resource, but not as an electricity generation resource. This way, each actor will use the electric energy that he himself feeds into the storage unit, so there will be no conflict of interest between actors in different auctions.

The energy balance requirement is also critical for the conduct of the auction chaining. As the auctions are taking place in order of descending length of horizons, a non-zero energy balance resulting from a subordinate auction might make the previously established profiles infeasible in future periods. Furthermore, as energy has value in itself, a net energy deviation will influence on the value that the bidders attach to their submitted profile. An illustrative example can be considered in which bidder A submits a profile with zero energy balance for the price of 100 , while bidder $B$ submits a profile with an energy deficit (discharging more energy than what it has injected into the storage) for the price of 120 . Then the winner of the auction will depend on whether the energy deficit is worth more than 20 or not. This information, however, will not necessarily be revealed before the gate closure of the underlined auction, but most probably only a posterior. In this case, the bid selection could become difficult. In addition, it raises another question that the value of energy deficit (or surplus) should ascribe to the storage operator or to the bidders in the next auction. Taking into account these factors, the energy balance constraint is imposed in each auction, so that the linkage of the auction chain as well as the bid selection can be facilitated. Therefore, it is stressed that in this work only storage is offered in the strict sense, i.e., not allowing for any resulting net injection or withdrawal (which might however be focus of future research).

The bid the actors submit consists of two parts: a utilization profile of the storage unit over the underlying period and one sole price for the desired utilization profile. The bidder who offers the highest price (thus who attaches the most value to use the storage unit upon that time horizon) will win the auction. ${ }^{3}$ Note that the utilization profile submitted will imply real energy charging and discharging at the delivery time and does not stand for the reservation of the charge and discharge capacity. The utilization profile defined as such presents the property of being able to be aggregated. As illustrated by the formula below, the final charging or discharging of the storage unit at a certain time is the result of several charging or discharging actions that different actors (actors $\mathrm{A}, \mathrm{B}$, and $\mathrm{C}$ ) have decided upon in different time horizon:

$\operatorname{charge}_{t}=\operatorname{charg}_{t}^{A}-$ discharge $_{t}^{B}+\operatorname{charg}_{t}^{C}$

This way, the use of the storage unit by different actors will result in only one final physical charging or discharging action, while the value of the storage unit will be the sum of the values that each actor attaches to the desired utilization profile. Hence, the aggregation of values of storage is achieved.

As a storage unit has limited charge, discharge and energy storage capacities, a coordination mechanism is needed to ensure the feasibility of aggregating several utilization profiles. This coordination is done by the organizer of the auction who communicates the retained utilization profiles of the previous

\footnotetext{
${ }^{3}$ The bidder who participates in the auction can be one single actor or be an aggregator who aggregates the desired utilization profiles of several actors. Therefore, the joint optimization of the use of storage by several actors within one auction is allowed in the presented model, as long as they submit one profile and one price. But as the optimization of utilization profile is an external part of the business model, for the sake of simplicity, we will only simulate simple optimization process for single actors in the case study in order to put more emphasis on the auction chaining process.
} 
Table 1

Conduction of the auctions.

\begin{tabular}{|c|c|c|c|c|}
\hline \multirow[t]{2}{*}{ Time horizon } & \multirow[t]{2}{*}{ Constraints to obey } & \multirow[t]{2}{*}{ Energy balance clearing ${ }^{a}$} & \multicolumn{2}{|l|}{ Bid } \\
\hline & & & Utilization profile & Price \\
\hline Week-ahead & Physical constraints of storage & At the end of week & Profile_week & Value_week \\
\hline Day-ahead & $\begin{array}{l}\text { Physical constraints of storage } \\
\text { Profile_week }\end{array}$ & At the end of day & Profile_day & Value_day \\
\hline$x$-Hour-ahead ${ }^{\mathrm{b}}$ & $\begin{array}{l}\text { Physical constraints of storage } \\
\text { Profile_week } \\
\text { Profile_day }\end{array}$ & At the end of day & Profile_xhour & Value_xhour \\
\hline Hour-ahead & $\begin{array}{l}\text { Physical constraints of storage } \\
\text { Profile_week } \\
\text { Profile_day } \\
\text { Profile_xhour }\end{array}$ & At the end of day & Profile_hour & Value_hour \\
\hline
\end{tabular}

${ }^{a}$ Refers to the time when the energy level in the storage should return to the previously established value.

${ }^{\mathrm{b}} x$ can be 12,8 , or 4 , or indeed any hour if we wish to introduce an auction with the gate closure time $x$-hour ahead of real time delivery.

auctions to the actors in the subsequent auction. All the actors in this auction are asked to submit their desired utilization profile and the corresponding price while respecting the utilization profiles previously established. In other words, the utilization profiles retained in the previous auctions are considered as firm constraints to be obeyed in the next auction. Each auction will end up with a utilization profile that extracts the highest value from the remaining capacities of storage.

Table 1 gives a schematic illustration of the conduction of the auctions.

\section{Model description}

As an application of the model, a case study is formulated in this section. In the case study, we consider an auction chain composed of three sequential auctions. The first auction is the week-ahead auction, in which we study how an electricity generation company (GenCo) would use the storage to lower the generation cost. The second auction is the day-ahead auction, in which we simulate the strategy of a trader who wants to use storage to capture arbitrage profit on the spot market. The third auction introduced is the hour-ahead auction, in which we consider the case of a Transmission System Operator (TSO) who would like to use the remaining capacities of storage to provide regulating energy in the real time. The main purpose is to demonstrate the linkage between the auctions held upon the different horizons. Other auction chains can be composed by auctions with lead-times different from what is illustrated in this paper, or composed in different ways. Finding the best auction chain is the subject for future research.

Note that the choice of the actor (and his desired service) in this study is just for illustration purpose. It suffices to replace the objective function by that of another actor if we want to simulate how other actors elaborate their bids in the same auction. Therefore, the model is able to incorporate any utilization profiles resulted from any optimization process. It is stressed that the core of the business model is to aggregate the utilization profiles upon different horizons using a coordination mechanism. One should note that in practice, the generation of the utilization profiles by bidders in each auction is independent from the described model, and is undertaken by individual actors themselves. The simulation of certain optimization processes in the case study only serves the purpose of demonstrating how the coordination of use of storage upon different horizons is realized.

In the remainder of the section, the developed optimization and coordination algorithms are presented for each auction.
Mixed-integer linear programming (MILP) and Mixed-integer quadratically constrained programming (MIQCP) models are used to solve the optimization problem for different actors. The model is implemented partly in Matlab and partly in GAMS (using the Matlab/GAMS link) and is solved using the Cplex 10.0 solver.

\subsection{Week-ahead auction}

In the week-ahead auction, a GenCo can use storage to lower his generation cost by avoiding the use of expensive peak units, and by economizing the part-load cost and start-up cost of power plants (which would have occurred in order to follow the timevarying load without the aid of storage). The use of storage will be optimized over the whole week. The objective function of the GenCo is a single cost function to be minimized, with $I$ the set of power plants (index $i$ ) and $T^{\prime}$ the set of time periods (index $t^{\prime}$ ), corresponding to $168 \mathrm{~h}$ of the week:

minimize obj $=\sum_{i} \sum_{t^{\prime}=1}^{168}\left(C F_{i, t^{\prime}}+C U_{i, t^{\prime}}\right)$

with $o b j$ is the total cost of electricity generation with storage $(€)$, $C F_{i, t^{\prime}}$ the fuel cost of plant $i$, hour $t^{\prime}$ of the week $(€)$, and $C U_{i, t^{\prime}}$ the start-up cost of plant $i$, hour $t^{\prime}$ of the week $(€)$.

A minimum operating point of a power plant is implemented, together with a stepwise cost function to account for the generation efficiency at different output levels. The minimum up- and downtime constraints of power plants are taken into account. We refer to Appendix A for the formulation of cost functions and constraints.

The constraint that enforces the satisfaction of the demand during all hours is written as

$\forall t^{\prime} \in T^{\prime}: d_{t^{\prime}}=\sum_{i} g_{i, t^{\prime}}-\operatorname{charg} e_{\mathrm{t}^{\prime}}^{\mathrm{w}}+\operatorname{discharg} e_{t^{\prime}}^{w}$

with $d_{t^{\prime}}$ is the electricity demand during hour $t^{\prime}$ of the week (MW), ${ }^{4} g_{i, t^{\prime}}$ the electricity generation of plant $i$ during hour $t^{\prime}$ of the week (MW), charge $t_{t^{\prime}}^{w}$ the charging power (storing energy) during hour $t^{\prime}$ of the week in the week-ahead auction (MW) discharge $e_{t^{\prime}}^{w}$ the discharging power (releasing energy from the storage) during hour $t^{\prime}$ of the week in the week-ahead auction (MW).

Supposing that there is no auction prior to the week-ahead auction, the operation of the storage unit is confined by the

${ }^{4}$ Throughout the paper, we assume constant power within the time interval considered, be it power produced, consumed, charged into the storage or discharged from the storage. 
physical ratings of the storage unit:

$\forall t^{\prime} \in T^{\prime}: 0 \leq$ charge $_{t^{\prime}}^{w} \leq S C$

$\forall t^{\prime} \in T^{\prime}: 0 \leq$ discharge $e_{t^{\prime}}^{w} \leq S D$

$\forall t^{\prime} \in T^{\prime}: 0 \leq E_{t^{\prime}}^{w} \leq S E$

with $E_{t^{\prime}}^{w}$ is the energy level in the storage after the charging or discharging action of storage unit at the end of hour $t^{\prime}$ of the week (MWh), SC the maximum charge capacity of the storage unit (MW), SD the maximum discharge capacity of the storage unit $(\mathrm{MW}), S E$ the maximum energy capacity of the storage unit (MWh).

Eq. (6) traces the energy level in the storage. There is an efficiency loss during the charging phase as well as during the discharging phase. The charge efficiency and the discharge efficiency are both considered equal to the square root of the round trip efficiency:

$\forall t^{\prime} \in T^{\prime}: E_{t^{\prime}}^{w}=E_{t^{\prime}-1}^{w}+\operatorname{charge}_{t^{\prime}}^{w} \mu T^{w}-\operatorname{discharge} e_{t^{\prime}}^{w} \frac{1}{\mu} T^{w}$

with $\mu$ is the charge or discharge efficiency of the storage unit (percentage), and $T^{w}$ the time interval considered in the weekahead auction, equal to $1(\mathrm{~h})$.

Eq. (7) enforces that the energy level at the end of the week should be equal to the energy level at the beginning of the week, which is the initial energy stored. The initial energy is set to the level that allows equal duration of charging and discharging at maximum capacity ${ }^{5}$ :

$E_{168}^{w}=E_{\text {initial }}=\frac{S D}{S D+S C} S E$

with $E_{\text {initial }}$ is the energy level in the storage at the beginning of the week (MWh).

After the closure of the week-ahead auction, the retained utilization profile for the $168 \mathrm{~h}$ of the week is transformed into the corresponding action at the hour $t$ of the day $j$, and will be entered as firm constraints to be respected in the day-ahead auction. Hence, charge $t_{t^{\prime}}^{w}$ discharge $t_{t^{\prime}}^{w}$, and $E_{t^{\prime}}^{w}$ ( with the set of time periods $T^{\prime}\{1,2, \ldots, 168\}$, with index $t^{\prime}$ ) are transformed to charge $e_{j, t}^{w}$, discharge $e_{j, t}^{w}$, and $E_{j, t}^{w}$, respectively, with $J$ the set of days $\{1,2, \ldots, 7\}$ (index $j$ ) and $T$ the set of hours $\{1,2, \ldots, 24\}$ (index $t$ ).

\subsection{Day-ahead auction}

In the day-ahead auction, we simulate the case of a trader who uses storage to do arbitrage in the day-ahead spot market. ${ }^{6}$ In order to understand the link between the week-ahead auction and the day-ahead auction, we will first introduce the notions of net action and remaining capacities, which are key to the coordination mechanism. Next, the optimization algorithm of the trader is presented.

\subsubsection{Net action and remaining capacities}

The actions (charging or discharging) desired by different actors in different auctions can add up or cancel out. It is important to keep in mind that the energy level change is related

\footnotetext{
${ }^{5}$ This assumption is intended to give the bidders more liberty of actions at the beginning of the auction period. As a comparison, setting the initial energy level at the minimum or maximum energy capacity of the storage unit will prevent the bidders from taking any discharging or charging actions, respectively, during the first periods.

${ }^{6}$ Note that GenCos bidding in the week-ahead auction can also take price forecasts into account when setting up their bids. The main focus of this paper is, however, to develop and demonstrate the coordination mechanism of the storage use.
}

only to the aggregated action on storage, because the efficiency loss is applied to the net energy charged into or discharged from the storage unit at a certain time. As a result, an action that is in the same direction of the action previously established will result in an increase of efficiency loss, whereas an action in the opposite direction could decrease the efficiency loss. The bidders are aware of the impact of their desired actions on the efficiency loss when implementing their optimization algorithm. For instance, a net efficiency gain will result from actions opposite to actions established in the previous auctions. After all, these opposite actions lead to a reduced actual (physical) use of the storage unit, and hence, to a reduced efficiency loss (i.e., net efficiency gain, collected by the actor conducting the opposite action). Hence, the notion of net action is introduced, which stands for the actual action implemented on the storage unit at a certain time. Mathematically the net action is defined as the difference between the implemented charging and discharging action, as shown in $(8)^{7}$

netaction $_{j, t}^{w}=$ charge $_{j, t}^{w}-$ discharge $_{j, t}^{w} \quad t \in(1,2, \ldots, 24)$

By this definition, a positive net action implies a charging action, while a negative net action implies a discharging action. As will be illustrated later in this section, the net action after the day-ahead auction will further include the day-ahead actions on the storage.

The net action will introduce another important notion being the remaining capacities of storage. They set the boundaries of allowed actions in the auction:

$R C_{j, t}^{d}=S C-$ netaction $w, t$

$R D_{j, t}^{d}=S D+$ netaction $w_{j, t}^{w}$

with $R C_{j, t}^{d}$ is the remaining charge capacity for hour $t$ of day $j$ in the day-ahead auction (MW), $R D_{j, t}^{d}$ the remaining discharge capacity for hour $t$ of day $j$ in the day-ahead auction (MW).

It is stressed that the "remaining capacities" so defined are in a commercial sense. ${ }^{8}$ For example, if the winner in the week-ahead auction wishes to discharge the storage at a certain time, Eq. (9) will allow the day-ahead bidder to charge the storage (in commercial sense) at a rate higher than the physical rating, as long as the sum of the week-ahead discharging action and the day-ahead charging action is lower than the maximum capacity rating of the storage unit. Similarly, if the week-ahead actor wishes to charge the storage at a certain time, bidders in the next round of auction would have possibilities to discharge beyond the physical discharge capacity. The storage unit, given its unique capacity of being able to operate in two directions, can accommodate perfectly the offsetting actions as described above, and can generate values for different actors with a limited power rating.

\footnotetext{
${ }^{7}$ Simultaneous charging and discharging actions are not allowed technically, so at least one of the charging and discharging actions in Eq. (8) takes the value of zero.

${ }^{8}$ The model conceived in the paper does not take into account the impact of possible network constraints on the "technically feasible" charging or discharging capacities of storage. Indeed, an offsetting action that is economically interesting for one actor may induce a network congestion that would cause additional cost to the power system. However, the current electricity markets are arranged such that it is not the task of individual market participant to deal with network constraint resulting from the commercial exchanges between them; the network operator will try to resolve congestion or any demand-supply imbalances in a central manner, in order to respect as much as possible the market results. That is why in the present model, the "remaining capacities" of storage are defined in commercial sense.
} 


\subsubsection{Day-ahead optimization considering market resilience}

In existing studies about the arbitrage value of storage, the spot market price of electricity is generally viewed as an exogenous variable which is independent of the operation of storage. However, this method would lead to an overestimation of storage's value. In fact, by storing at low prices and discharging at high prices, the storage may reduce the inter-temporal price spread, leading to less arbitrage value than anticipated. In the presented analysis, a market resilience factor ${ }^{9}$ is incorporated into the optimization algorithm of the trader. As indicated by the objective function below, the trader would anticipate the impact of its charging or discharging action on the market price and would take this impact into account when deciding the optimal arbitrage strategy.

The objective function of the trader is written as

$$
\begin{aligned}
\forall j \in J: \text { maximize profit }= & \sum_{t=1}^{24}\left(\operatorname{discharge}_{j, t}^{d} T^{d}\left(P_{j, t}+\operatorname{discharge}_{j, t}^{d} T^{d} \text { resil }\right)\right. \\
& \left.-\operatorname{charge}_{j, t}^{d} T^{d}\left(P_{j, t}-\operatorname{charg} e_{j, t}^{d} T^{d} \text { resil }\right)\right)
\end{aligned}
$$

with charge $_{j, t}^{d}$ is the charging power (storing energy) during hour $t$ of day $j$ in the day-ahead auction (MW), discharge ${ }_{j, t}^{d}$ the discharging power (releasing energy from the storage) during hour $t$ of day $j$ in the day-ahead auction (MW), resil the resilience factor indicating the price change due to an increase in supply or demand offer on the market $(€ / M W h / M W h)$. It is by definition negative. profit is the maximum arbitrage profit $(€), P_{j, t}$ the dayahead spot price at hour $t$ of day $j(€ / \mathrm{MWh}), T^{d}$ is the time interval considered in the day-ahead auction, equal to 1 (h)

As stated before, the desired utilization of the storage unit in the day-ahead auction should respect the utilization profile established in the precedent auction. The allowed actions in the day-ahead auction are bounded by the remaining charge and discharge capacities after the week-ahead use of storage:

$\forall j \in J, \quad \forall t \in T: 0 \leq$ charge $_{j, t}^{d} \leq R C_{j, t}^{d}$

$\forall j \in J, \quad \forall t \in T: 0 \leq \operatorname{discharg} e_{j, t}^{d} \leq R D_{j, t}^{d}$

The net action after the day-ahead use of storage is written as $\forall j \in J, \quad \forall t \in T:$ netaction $_{j, t}^{d}=\operatorname{charg}_{j, t}^{w}+\operatorname{charg}_{j, t}^{d}-$ discharge $_{j, t}^{w}-$ discharge $_{j, t}^{d}$

Eq. (15) gives the inter-temporal energy level changes in the storage due to the aggregated action after the week-ahead and dayahead auctions. The avoided efficiency loss because of the offsetting actions in the two auctions is taken into account by netaction $n_{j, t}^{d}$ :

$$
\begin{aligned}
\forall j \in J, \quad \forall t \in T, t \neq 1: E_{j, t}^{d}= & E_{j, t-1}^{d}+\text { netaction }_{j, t}^{d} y_{j, t}^{d} \mu T^{d} \\
& + \text { netaction }_{j, t}^{d}\left(1-y_{j, t}^{d}\right) \frac{1}{\mu} T^{d}
\end{aligned}
$$

with $E_{j, t}^{d}$ is the energy level in the storage after the charging or discharging action at the end of hour $t$ of day $j$ in the day-ahead auction (MWh), netaction $n_{j, t}^{d}$ the net action on the storage unit during hour $t$ of day $j$ after the day-ahead use of storage (MW), $y_{j, t}^{d}$ the binary indicating whether the net action after the day-ahead use of storage is charging the storage unit or not: 1 if yes, 0 if not. ${ }^{10}$

\footnotetext{
${ }^{9}$ Market resilience indicates the price sensitivity to an increase in supply or demand offer in a certain market (Belpex, 2010b).

${ }^{10}$ In the actual model, two auxiliary variables are created for net action (one positive or zero and one zero or negative), using the binary variable $y$, so as to keep these equations linear.
}

For the first hour of the day, the $E_{j, t-1}^{d}$ in (15) is replaced by the corresponding energy level at the beginning of the day which is established in the week-ahead auction.

Eq. (16) sets the minimum and maximum limits of the energy level after the day-ahead use of the storage. Eq. (17) enforces that for each day $j$, the energy level at the last hour should be equal to the energy level established in the week-ahead auction. It means that the day-ahead use of storage should result in zero net energy change at the end of day:

$\forall j \in J, \quad \forall t \in T: 0 \leq \mathrm{E}_{j, t}^{d} \leq S E$

$\forall j \in J: E_{j, 24}^{d}=E_{j, 24}^{w}$

\subsection{Hour-ahead auction}

According to the current market arrangements, all the commercial power exchanges are closed at least $1 \mathrm{~h}$ ahead of real time delivery of power. The TSO could still use the remaining storage capacities to provide regulating energy in real time. This conduct will not generate a conflict with the commercial use of storage, and will make economic sense for the power system. On the one hand, the energy cost to activate conventional regulation reserve could be avoided if the required regulation power is provided by storage. On the other hand, if the storage is proved to be able to systematically supply a certain amount of regulation power when required, the total reserve requirement ascribed to conventional means could be reduced without compromising the reliability of the system, and more capacity could be released for energy production. Above all, from a technical point of view, the storage technologies generally outperform other conventional generation means to prevent frequency excursions in case of system contingencies, because of very short reaction time and high ramp rates of storage technologies (Aditya and Das, 2001).

In our simulation, the system operator will maximize the use of remaining storage capacities to provide regulating energy instead of resorting to other less flexible production plants. Due to the physical law of frequency regulation, the charging or discharging action on storage depends solely on the direction of the regulation required. The system operator can decide to activate or not the storage unit to provide the required regulation. By using the storage capacities on real time basis, there is inevitably an energy balance deviation at the end of $1 \mathrm{~h}$ or of the day. The previously established utilization profiles might not be respected. In order to avoid such situation to occur, in the hour-ahead model we enforce that the TSO would operate the storage only during the first $23 \mathrm{~h}$ of the day. The last hour is reserved for the final adjustment action. ${ }^{11}$ A verification procedure will be launched during the first $23 \mathrm{~h}$ to ensure that the hour-ahead use of storage will not disturb the previously established utilization profiles, and that there is enough offsetting capacity during the last hour of the day to bring the energy level back to the targeted value.

\subsubsection{Estimation of hour-ahead use of storage-two approaches}

In reality, the TSO disposes of dynamic models and simulation software to simulate the short term and transient dynamics of the power system and can have a quite accurate estimation of the use of storage in real time. This paper does not endeavor to replicate the same analysis as the commercial software, but is aimed at demonstrating how the hour-ahead use of storage can be incorporated in the business model. To this purpose, two approaches are developed that would set the maximum and minimum boundaries of the hour-ahead use of storage.

\footnotetext{
${ }^{11}$ Note that leaving the last hour for adjustment is an arbitrary assumption which might not be the optimal regarding the expected pattern of energy and regulation prices.
} 
3.3.1.1. First approach: perfect foresight. The first approach assumes full foresight over the regulation direction and volume during the whole day. The objective function of the TSO is to maximize the use of storage to provide regulation power during the first $23 \mathrm{~h}$ of a day:

$\forall j \in J, \quad \forall t \in(1,2, \ldots, 23):$ maximize obj $=\sum_{q=1}^{4}\left(\right.$ charge $e_{j, t, q}^{h}+$ discharge $\left._{j, t, q}^{h}\right)$

Note that a new set $Q$ is introduced (with index $q$ ), for the time periods within set $T$. In this case, every hour $t$ is split into 4 quarters $Q=\{1,2,3,4\}$.

The available storage capacities for the hour-ahead auction are given by Eqs. (19) and (20). Recall that the net action on the storage unit after the day-ahead auction is given by (14):

$\forall j \in J, \quad \forall t \in(1,2, \ldots, 23): R C_{j, t}^{h}=S C-$ netaction $_{j, t}^{d}$

$\forall j \in J, \quad \forall t \in(1,2, \ldots, 23): R D_{j, t}^{h}=S D+$ netaction $_{j, t}^{d}$

with $R C_{j, t}^{h}$ is the remaining charge capacity for hour $t$ of day $j$ in the hour-ahead auction (MW), $R D_{j, t}^{h}$ the remaining discharge capacity for hour $t$ of day $j$ in the hour-ahead auction (MW).

The charging or discharging action implemented by the TSO within $1 \mathrm{~h}$ should be less than the remaining charge or discharge capacity, as well as the downward or upward regulation power requirement:

$\forall \mathbf{j} \in J, \quad \forall \mathrm{t} \in(1,2, \ldots, 23), \quad \forall q \in Q: 0 \leq$ discharge $_{j, t, q}^{h} \leq R D_{j, t}^{h}$

$0 \leq$ discharge $_{j, t, q}^{h} \leq$ regulation $_{j, t, q} b_{j, t, q}$

$\forall \mathrm{j} \in J, \quad \forall t \in(1,2, \ldots, 23), \quad \forall q \in Q: 0 \leq \operatorname{charg}_{j, t, q}^{h} \leq R C_{j, t}^{h}$

$0 \leq$ charge $_{j, t, q}^{h} \leq$ regulation $_{j, t, q}\left(b_{j, t, q}-1\right)$

with $b_{j, t, q}$ is the binary parameter (input data) indicating whether an upward regulation is taking place at quarter $q$ of hour $t$, day $j: 1$ if upward regulation, 0 if downward regulation. charge ${ }_{j, t, q}^{h}$ the charging power (storing energy) during quarter $q$ of hour $t$, day $j$ in the hour-ahead auction (MW), discharge $e_{j, t, q}^{h}$ the discharging power (releasing energy from the storage) during quarter $q$ of hour $t$, day $j$ in the hour-ahead auction (MW), and regulation $n_{j, t, q}$ the system's requirement of the upward or downward regulation; positive if upward regulation, negative if downward regulation (MW).

Eq. (23) calculates the net action after the hour-ahead use of storage:

$\forall j \in J, \quad \forall t \in(1,2, \ldots, 23), \quad \forall q \in Q$ :

netaction $_{j, t, q}^{h}=\left(\operatorname{charg}_{j, t}^{w}+\operatorname{charg}_{j, t}^{d}+\operatorname{charg}_{j, t, q}^{h}\right)$

$$
-\left(\operatorname{discharg} e_{j, t}^{w}+\operatorname{discharg} e_{j, t}^{d}+\operatorname{discharg} e_{j, t, q}^{h}\right)
$$

Eq. (24) traces the energy level after the hour-ahead use of storage:

$\forall j \in J, \quad \forall t \in(1,2, \quad 23), \quad \forall q \in Q, q \neq 1$ :

$E_{j, t, q}^{h}=E_{j, t, q-1}^{h}+$ netaction $_{j, t, q}^{h} y_{j, t, q}^{h} \mu T^{h}+$ netaction $_{j, t, q}^{h}\left(1-y_{j, t, q}^{h}\right) \frac{1}{\mu} T^{h}$

with $T^{h}$ is the time interval considered in the hour-ahead auction, equal to $1 / 4(\mathrm{~h}), y_{j, t, q}^{h}$ the binary indicating whether the net action after the hour-ahead use of storage is charging the storage unit or not: 1 if yes, 0 if not.

For the first quarter of the hour, the $E_{j, t, q-1}^{h}$ in (24) should be replaced with the corresponding energy level at the beginning of the hour which is established in the previous auctions.
Eq. (25) counts the net energy deviation at the end of each quarter. This variable is created for the verification procedure:

$\forall j \in J, \quad \forall t \in(1,2, \ldots, 23), \quad \forall q \in Q: \sigma_{j, t, q}=E_{j, t, q}^{h}-E_{j, t}^{d}$

with $\sigma_{j, t, q}$ is the net energy level shift at the end of quarter $q$, hour $t$ of day $j$ because of the hour-ahead use of storage (MWh).

Apart from the constraints listed above, we also need to ensure that the hour-ahead actions on the storage will not infringe on the utilization profiles established in the previous auctions. The perfect foresight assumption implies that the TSO knows all the opportunities of offsetting regulation actions in the following hours. Hence, we only need to ensure that the energy level at any time remains within the technical limitations with constraint (26), and that there is sufficient offsetting capacity during the last hour of the day to correct the energy deviation at the end of the 23rd hour, as enforced by (27):

$\forall j \in J, \quad \forall t \in(1,2, \ldots, 23), \quad \forall q \in Q: 0 \leq E_{j, t, q}^{h} \leq S E$

$\forall j \in J:-R C_{j, 24}^{h} \leq \sigma_{j, 23,4} \leq R D_{j, 24}^{h}$

3.3.1.2. Second approach: no foresight. The second approach estimates the use of storage with the assumption that the system operator has no knowledge of the regulation requirement on the following hours. In this case, the decision whether to activate the storage to provide regulation power at a certain time is made as if there would be no offsetting actions during the following hours. Therefore, in contrast to the perfect foresight approach, there is no inter-temporal optimization of the use of storage under the no foresight assumption. At each time step, the implemented hourahead action will be decided through a procedure described by Fig. 1. At each time step, the desired action, which is the lower value of residual capacity and required regulation power, will be verified by Eqs. (28) and (29).

Eq. (28) verifies whether there is sufficient offsetting capacity during all the following hours to compensate the energy deviation caused by the hour-ahead use of storage. If not, the storage will not be activated to provide the regulation power:

$\forall j \in J, \quad \forall t \in(1,2, \ldots, 23), \quad \forall k \in(t+1, t+2, \ldots, 24), \forall q \in Q$ :

$-\sum_{k=t+1}^{24} R C_{j, k}^{h} \leq \sigma_{j, t, q} \leq \sum_{k=t+1}^{24} R D_{j, k}^{h}$

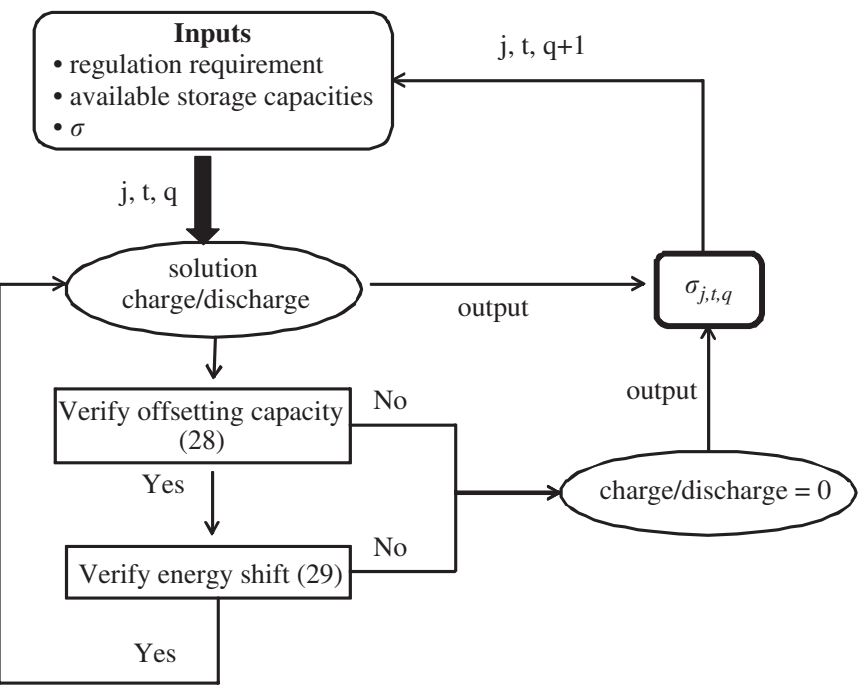

Fig. 1. Calculation of hour-ahead use of storage under the no-foresight assumption, based on the verification procedure. 
In addition, it also needs to be ensured that the energy level change following the hour-ahead use of storage will not shift the energy level out of the maximum and minimum limits for all the following hours. Otherwise, the storage will not be activated to provide the regulation power. The set of Eqs. (29) is created towards this aim:

$\forall j \in J, \quad \forall t \in(1,2, \ldots, 23), \quad \forall q \in Q$ :

$0 \leq \sigma_{j, t, q}+E_{j, t}^{d} \leq S E$

$0 \leq \sigma_{j, t, q}+E_{j, t+1}^{d} \leq S E$

$0 \leq \sigma_{j, t, q}+E_{j, 24}^{d} \leq S E$

This verification procedure is carried out for each quarter according to the time sequence, as illustrated by Fig. 1. The results obtained will be the decided charging/discharging action at each time step, as well as the accumulated energy deviation $\left(\sigma_{j, t, q}\right)$ at the end of this time step. These results will then be entered as inputs in the verification procedure of the next quarter.

Finally the uses of storage upon the whole period will be summed up to obtain the total hour-ahead use of storage under the no-foresight assumption:

$\forall j \in J, \quad \forall t \in(1,2, \ldots, 23), \quad \forall q \in Q$ :

total_use $=\sum_{j=1}^{7} \sum_{t=1}^{23} \sum_{q=1}^{4}\left(\right.$ charge $_{j, t, q}^{h}+$ discharge $\left._{j, t, q}^{h}\right)$

with total_use: total use of storage in the hour-ahead auction (MWh).

The results calculated under these two assumptions should set the maximum and minimum boundaries of the use of storage to provide regulation power.

\section{Case study}

This section demonstrates the functioning of the business model in a case study. First the input data for each of the auctions simulated are described. Second, the simulation results are presented and analyzed.

\subsection{Simulation setup}

The technical parameters of the storage unit in study are shown in Table 2. The storage unit features different charge and discharge capacities. It can fill the energy reservoir at maximum charging rate within $6 \mathrm{~h}$, and can withdraw all the stored energy within $3 \mathrm{~h}$ at maximum discharging rate. Such setup is intended to highlight the fact that in many cases, the storage unit can be dimensioned to have different charging and discharging rate, which may lead to better economic performance. ${ }^{12}$

In the week-ahead auction, the GenCo is supposed to possess a portfolio of base-load (nuclear plant), medium-load (coal plant and CCGT), and peak-load generation units (gas and oil-fired peaking units), with a total generation capacity of $1740 \mathrm{MW}$. We refer to Delarue (2009) as the source of data. The load pattern is derived from the actual Belgium load profile (Elia, 2010).

The simulations are carried out for the fourth week of 2007 as a demonstration of the functioning of the business model.

${ }^{12}$ An intuitive evidence is that, as low prices in spot market generally last much longer than peak prices, it makes economic sense to have low charge rate but high discharge rate to achieve higher profit.
Table 2

Storage unit characteristics.

\begin{tabular}{llllll}
\hline Storage unit & SC (MW) & SD (MW) & SE (MWh) & $\mu_{\text {charge }}(\%)$ & $\mu_{\text {discharge }}(\%)$ \\
\hline 200 & 400 & 1200 & 90 & 90 \\
\hline
\end{tabular}

SC: maximum charge capacity of the storage unit (MW); SD: maximum discharge capacity of the storage unit (MW); SE: maximum energy storage capacity of the storage unit (MWh); $\mu$ : storage conversion efficiency (percentage).

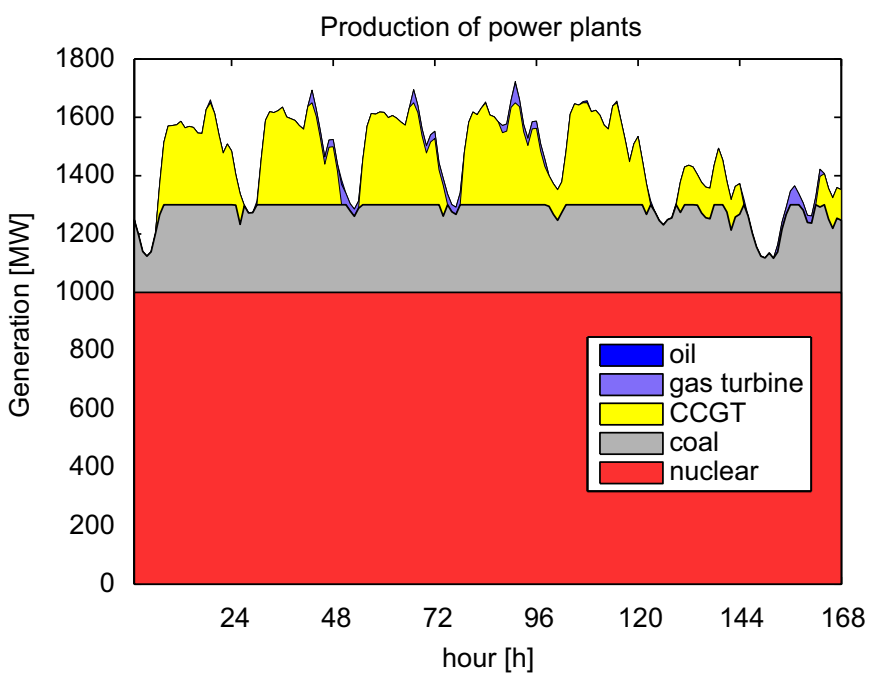

Fig. 2. Electricity generation without storage.

In the day-ahead auction, the Belpex (Belgian Power Exchange) spot prices of the fourth week of 2007 (Belpex, 2010a) are used in the simulation. The resilience factor is set to be -0.01 , which is a reasonable value according to the information provided by Belpex (2010b).

In the hour-ahead auction, the Belgian regulation prices and volumes during the fourth week of 2007 (Elia, 2010) are used for simulation.

\subsection{Simulation results}

In this section, the simulation results for the three auctions are presented and analyzed.

\subsubsection{Week-ahead auction}

In the week-ahead auction, the GenCo will first estimate its generation cost without storage. As shown by Fig. 2, the coal plant and the peaking units are the main units to follow the load variations, resulting in high fuel costs and operating at lower part-load efficiencies.

Fig. 3 shows that, with the help of the storage unit, the GenCo can minimize the use of expensive peak-load unit and largely avoid part-load losses. Fig. 4 shows the desired utilization profile of storage during the underlying week. The value that the GenCo attaches to this utilization profile can be considered as the difference between the total cost of meeting the demand without storage and that with storage.

\subsubsection{Day-ahead auction}

In the day-ahead auctions, traders can optimize the use of remaining capacities of the storage unit to make arbitrage profit in the spot market. Fig. 5 shows the allowed actions in the day-ahead auction after the week-ahead use of storage. As one can note, the allowed actions can go beyond the physical power 


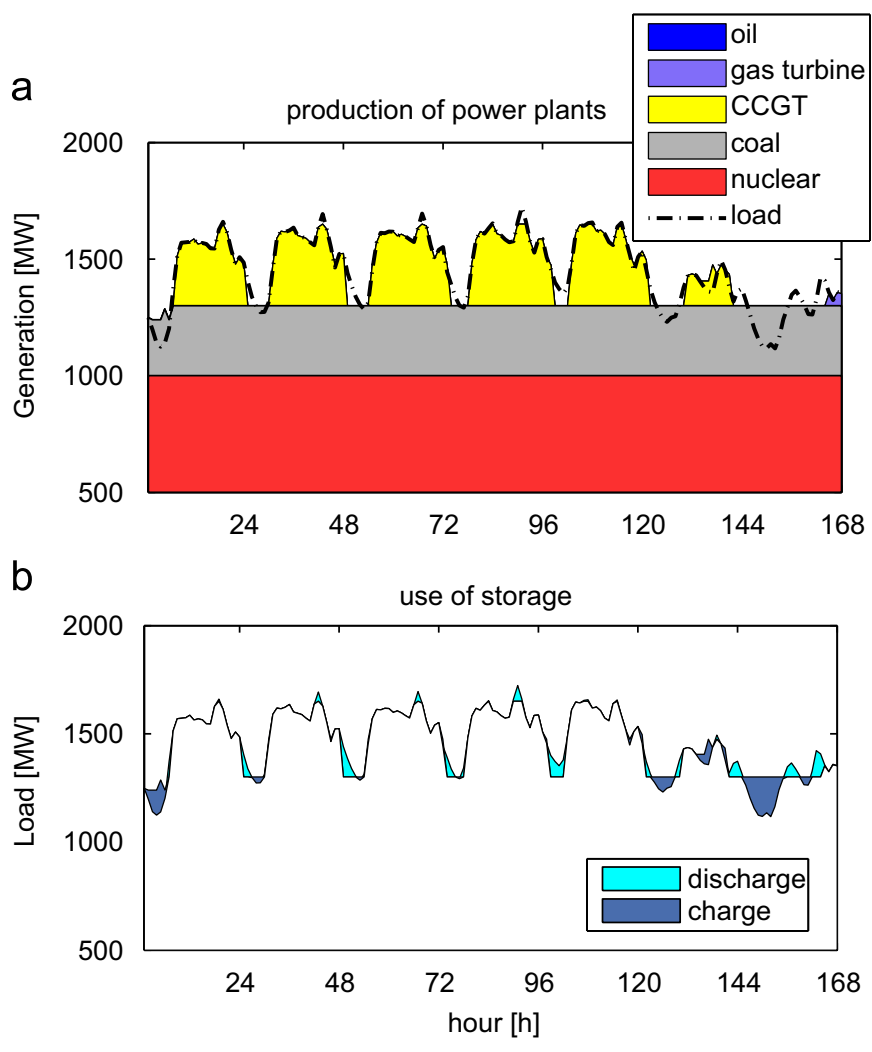

Fig. 3. (a) Production of power plants with the help of storage and (b) use of storage to reduce the total generation cost during the week.

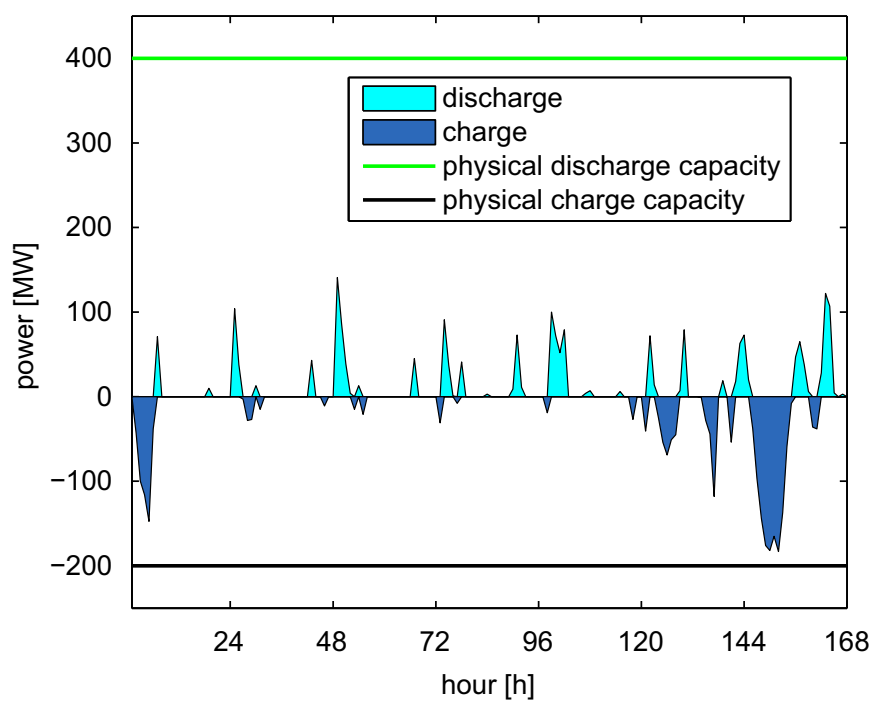

Fig. 4. Week-ahead actions on storage.

rating of the storage, because the week-ahead actions on storage create more room for the counteracting actions in the subsequent auction.

The case study results show that the week-ahead use of storage only occasionally impedes the trader to charge or discharge at the maximum capacity in the day-ahead action, and this constraint is very limited. On the contrary, during some hours, for instance at the beginning of the fifth day, the week-ahead charging actions on the storage allow for extra discharge capacity in the day-ahead auction. When this period happens to coincide

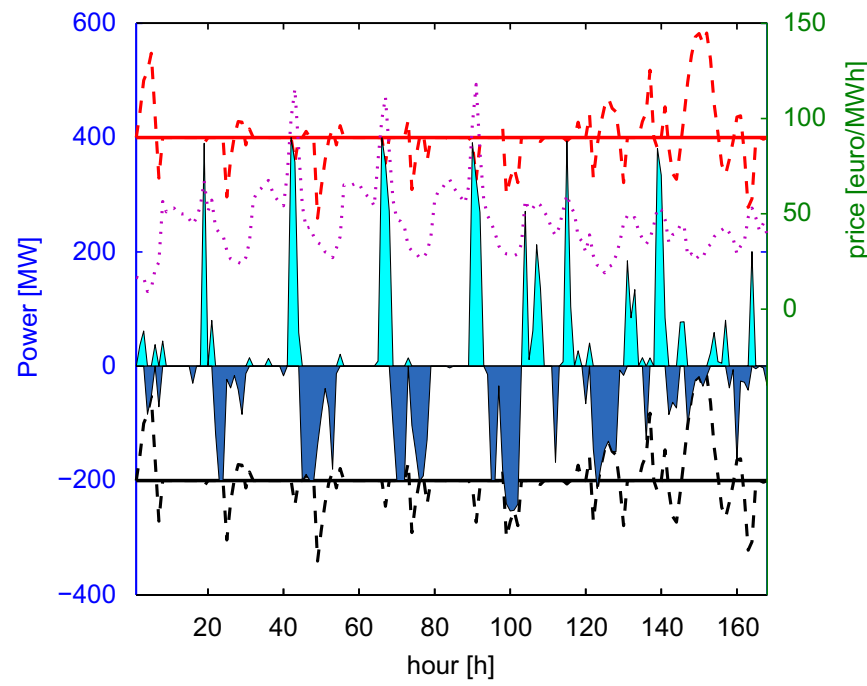

$$
\begin{aligned}
& \text { - - - remaining discharge capacity } \square \text { day-ahead discharge } \\
& \text { - - - remaining charge capacity } \\
& \text { - physical discharge capacity } \\
& \text { physical charge capacity } \\
& \text { day-ahead charge } \\
& \text { spot price }
\end{aligned}
$$

Fig. 5. Day-ahead charge and discharge actions, together with the allowed actions in day-ahead auction. Dashed curves depict the remaining charge and discharge capacities after the week-ahead use of storage. Full lines present the physical maximum charge and discharge capacity of the storage unit. The electricity spot price is presented by the dotted line.

with high prices in the day-ahead spot market, the trader can benefit from the week-ahead use of storage by selling more energy than the physical discharge capacity of storage. Overall it turns out that the week-ahead use of storage has very little effect in reducing the potential value of day-ahead use of the storage. However, one should note that this finding depends to a great extent on the obtained utilization profile established in this specific week-ahead auction. ${ }^{13}$

The day-ahead charging and discharging program shown in Fig. 5 represents the utilization profile of storage that maximizes the arbitrage profit of the trader in the spot market. The arbitrage profit can be considered as the value that the trader attaches to the corresponding utilization profile. We find that the market resilience has a considerable impact on the optimal strategy, as well as on the arbitrage value of the storage. If no market resilience is taken into account, the arbitrage value of the storage tends to be overestimated by nearly $20 \%$ in the same case setting.

Fig. 6 presents the aggregated charging/discharging action after the week-ahead and the day-ahead auction. As enforced by the algorithm, there is no simultaneous charging and discharging action at any time and the aggregated action is always less than the maximum charge or discharge capacity of the storage unit.

Fig. 7 shows that after the day-ahead use of storage, the energy level at the end of the day is always equal to the value established in the week-ahead auction, in spite of all the deviations happened within the day. This results from the fact that the day-ahead utilization profile is set up in such a way that the net energy level change caused by the day-ahead use of storage is zero. The storage unit is used as a pure flexibility resource.

\footnotetext{
${ }^{13}$ Recall that in this case, a cost based week-ahead optimization is used. However, one might also use a week-ahead optimization based on (imperfect) price forecasts, which would then result in a week-ahead profile that is more in line with the day-ahead profiles.
} 


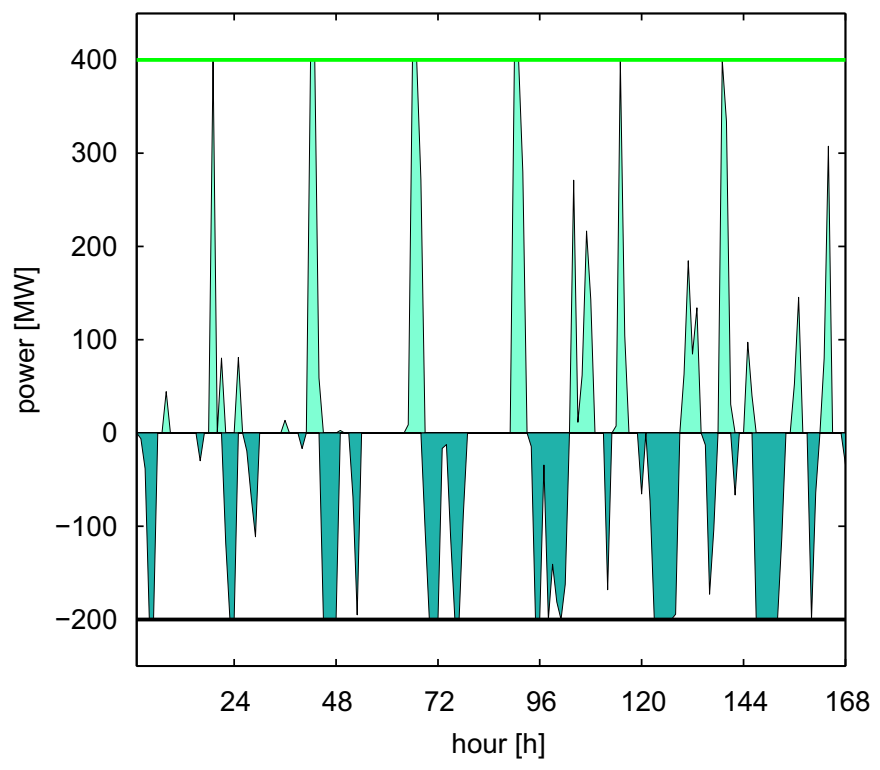

aggregated discharge aggregated charge

physical discharge capacity physical charge capacity

Fig. 6. Aggregated action of week-ahead and day-ahead auction. The aggregated actions are limited by the physical maximum charge and discharge capacities of the storage unit.

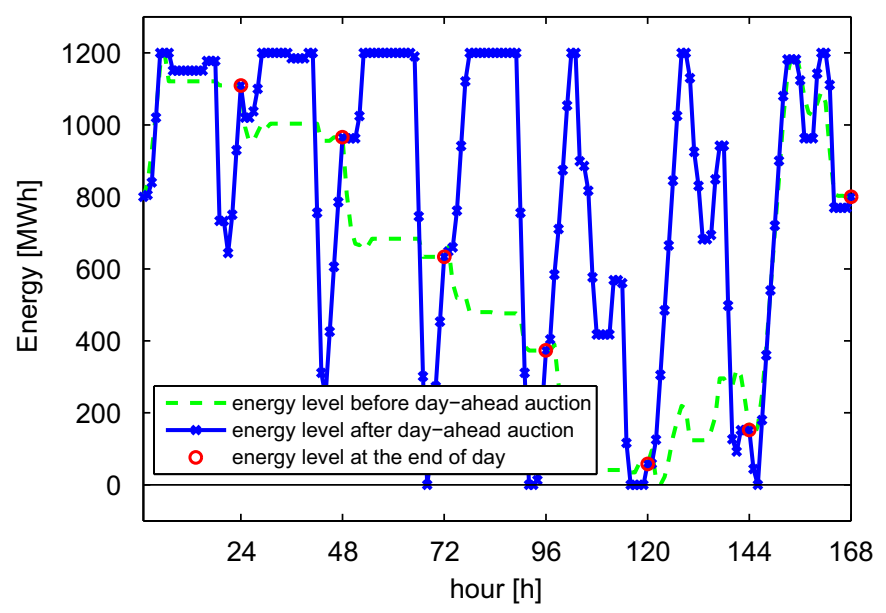

Fig. 7. Aggregated energy level after the day-ahead use of storage as compared to the energy level before the day-ahead auction.

\subsubsection{Hour-ahead auction}

In the hour-ahead auction, we simulate the use of the remaining storage capacities by the TSO to provide regulation power within $1 \mathrm{~h}$. The figures presented hereafter correspond to the case where we assume a perfect foresight on the regulation requirement by the TSO.

Fig. 8 shows the allowed actions in the hour-ahead auction after the two previous auctions. One can see that the hour-ahead actions are oscillating on small time steps as compared to the week- or day-ahead utilization profile. According to the simulation results under the perfect foresight assumption, the storage is able to supply regulation power for $67 \%$ of the time when a certain regulation (upwards or downwards) is required. Given the small volume of regulation power required at each step of $15 \mathrm{~min}$ (generally between $\pm 150 \mathrm{MW}$ ), when the storage unit is able to supply regulation power, it can, for the most of time, meet the total regulation requirement of the system. Under the no foresight

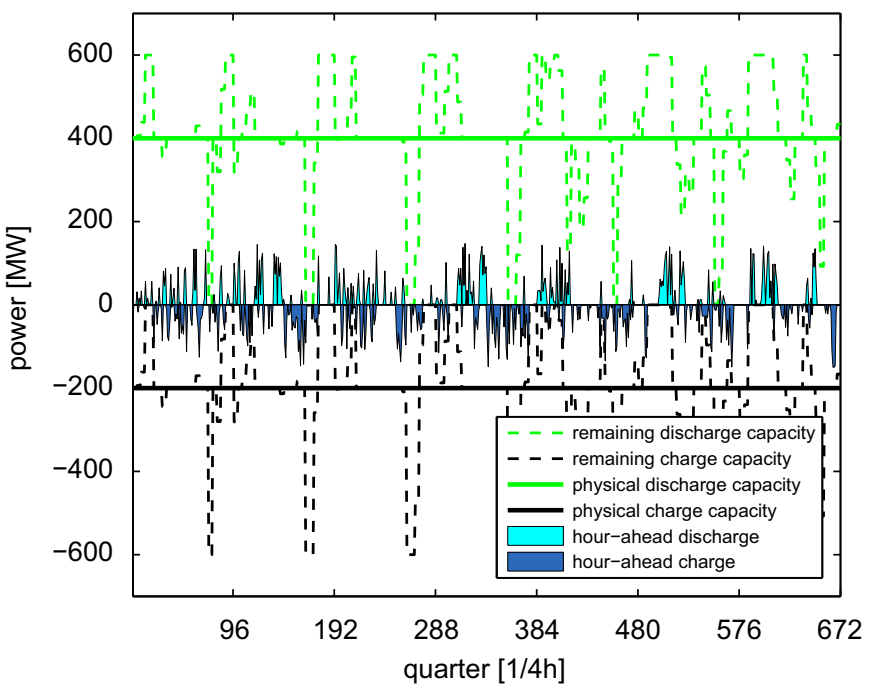

Fig. 8. Hour-ahead charge and discharge actions, together with allowed actions in the hour-ahead auction. Dashed curves depict the remaining charge and discharge capacities after the week-ahead and day-ahead use of storage. Full lines present the physical maximum charge and discharge capacity of the storage unit.

assumption, the availability of storage to provide regulation power is reduced to $48 \%$. These results show that, without reserving storage capacities on purpose for the supply of regulation power, the storage unit is still able to provide an important amount of regulation power in real time. This potential should be recognized and is worth further reflection, as it suggests that the storage unit, by supplying the regulation power with residual capacities after commercial trading, could eventually replace a certain amount of firm regulation reserve in the power system.

The hour-ahead utilization profile is then superposed on the aggregated week- and day-ahead use of storage, giving the aggregated utilization profile after the three auctions. The aggregated actions always lay within the physical power rating of the storage unit, as shown in Fig. 9.

Fig. 10 shows the aggregated energy level in the storage after the hour-ahead auctions. The hour-ahead use of storage to provide regulation power is translated into the small oscillations on the energy level. The energy level at the end of the day always returns to its due value because of the final adjustment action.

\subsection{Aggregated value versus single value}

Fig. 11 shows the single value of storage if it is used only by one of the three actors, as opposed to the aggregated value of storage following the auction chain. The monetary unit of value is euro. Recall that the simulations are undertaken for the fourth week of 2007. The hour-ahead value of storage is calculated by applying the marginal price for activating the required regulation power to the volume of regulation power supplied by the storage. ${ }^{14}$ The hour-ahead value shown in Fig. 11 corresponds to the perfect foresight assumption. Under the no foresight assumption, this value is about $26 \%$ less.

As explained before, in the case study the week-ahead use of storage interferes little with the day-ahead use of storage. In fact, we find that the day-ahead value in the auction chain is even slightly higher than in the case of only day-ahead use of storage. It is explained by the fact that the week-ahead use of storage

${ }^{14}$ As TSO incurs cost while activating upward regulation and revenue while activating downward regulation, the value of storage is the difference between the avoided cost and missed revenue. 


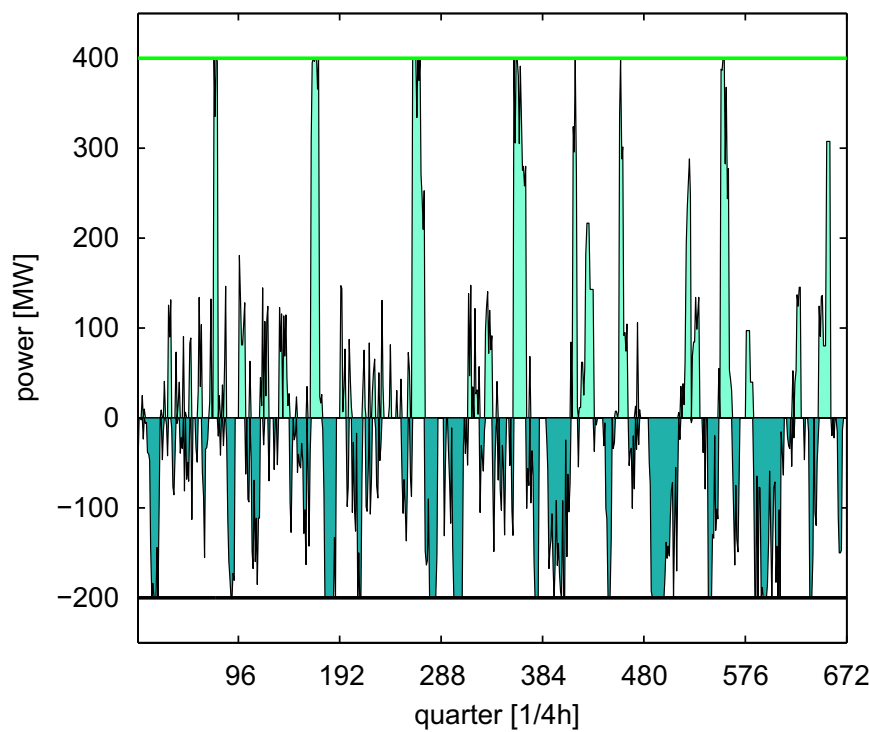

aggregated discharge aggregated charge

physical discharge capacity physical charge capacity

Fig. 9. Aggregated week-, day- and hour-ahead utilization profile.

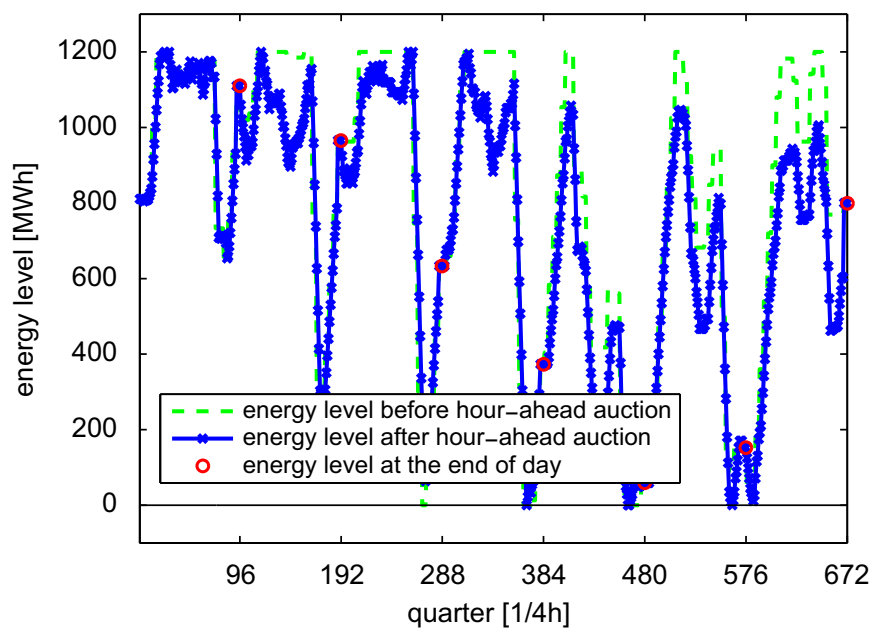

Fig. 10. Aggregated energy level after the hour-ahead auction as compared to the energy level before the hour-ahead auction.

sometimes makes it possible for the day-ahead user to charge/ discharge at capacity higher than the physical power rating. If the storage unit is dedicated only for regulation service, it can supply the regulation power for around $90 \%$ of time both under the perfect foresight and the no foresight assumption. As presented before, the availability of storage for supplying regulation power is reduced to $50-60 \%$ when the use of storage is integrated in the auction chain. However, the monetary benefit of using storage exclusively for regulation is not much higher than that in the auction chain, as shown by the third and fourth columns in Fig. 11. This is because using storage to supply upward and downward regulation entails the cash flows that would compensate each other. According to the simulation results, it is obvious that the aggregated value is much more important than any single value of storage. However, the exact amount of storage's value in each auction depends essentially on the specific case setup and the input data. The numerical results should therefore be interpreted with caution.

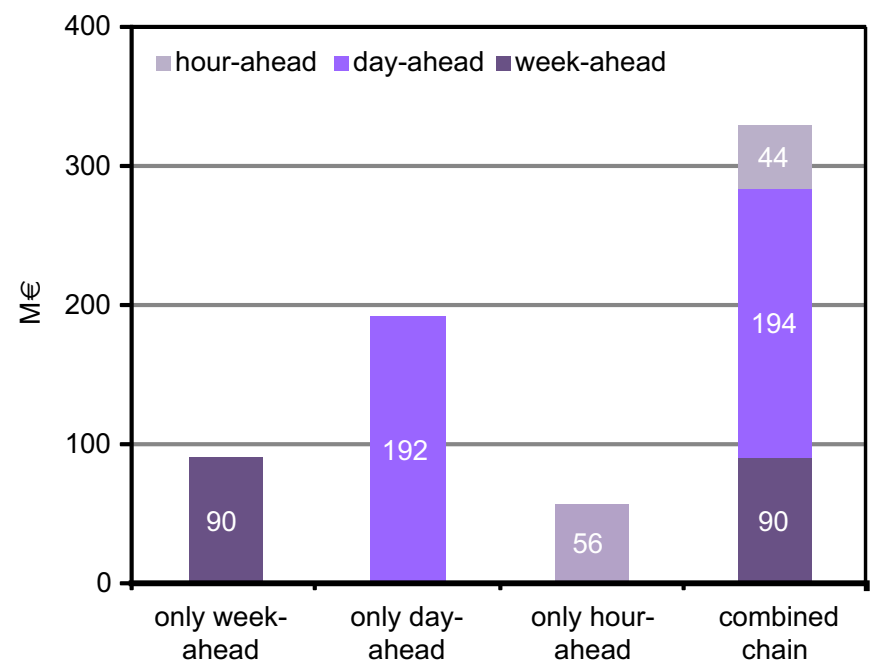

Fig. 11. Aggregated value versus single value.

\section{Discussion and conclusions}

This paper presents a new business model which enables to aggregate the values of storage in the liberalized electricity sector. The core idea of the model lies in organizing an auction chain in which the right to use available capacities of storage is auctioned among different actors. The aggregation of values is achieved by superposing the utilization profiles resulting from the chaining auctions. The model proves that it is technically possible to coordinate the use of the storage unit by different actors. The simulation results show that a storage unit can better recover its investment cost by aggregating the value of storage to different actors/services in the manner described in this business model.

The coordination algorithm proposed in the model is a generic one and is able to coordinate any utilization profiles without the need to know the underlying service. So the model is ready to simulate more case studies on other applications of storage. More importantly, the generic coordination algorithm is crucial to introduce sufficient and fair competitions among all actors in each auction.

The business model represents an attempt to solve the current investment puzzle of electricity storage units. The economic viability of electricity storage technologies have been long sought, but never achieved in a general sense. One important reason is the lack of a proper mechanism which allows the investor to capture the overall value of storage by providing multiple services to the power system. The efforts to aggregate several revenue streams of storage often encounter the regulatory obstacles which forbid the exchange of information between different actors, especially between the regulated actors and deregulated actors. In the proposed business model, the information about the use of storage is summarized in the utilization profile resulting from the auction, and is shared among all the actors in the next auction as a common constraint to obey. On top of that, a market rule is applied to select the winner in an auction. The product offered in the auctions is storage in the strict sense. This means that every actor has to ensure the balance between his injections and withdrawals, having a net zero injection or withdrawal at the end of the considered time horizon. Allowing for net-actions (without compensation) might be subject for future research.

In the case study, we have shown how a TSO can use the remaining capacities of storage after the closure of commercial exchanges in order to provide regulation power in the real time. This conduct seems to be consistent with the current regulation that prevents the regulated actors to touch the commercial 
activities. In this model, the TSO neither takes ownership over the storage unit (which is generally not allowed by the regulation in Europe), nor interferes with the commercial use of storage. It is considered as a viable way to allow aggregating the "deregulated" and "regulated" values of storage. Still, regulation is believed to plays the key role in the development of electricity storage. The lack of specific regulation for storage would lead to high investment uncertainties, while a regulation that fails to recognize the value of storage for the whole system would constitute a barrier for the deployment of storage in the power system. Once the storage is recognized as a "system" resource, as it actually is, we have reasons to believe that the cost of storage should be recovered by both the "deregulated" values and "regulated" values. Hence, the challenge for the policymakers and regulators is to design appropriate mechanisms to coordinate the use of storage with credible signals and without bias to specific actors. The business model proposed in the paper could add to the reflections on this issue.

\section{Appendix A. Model formulation}

A stepwise cost function of a power plant is introduced to account for the production efficiency at different output levels. Fig. 12 provides a graphical interpretation of some of the parameters and variables used as follows:

$g_{i, t^{\prime}}=\operatorname{Pmin}_{i} z_{i, t^{\prime}}+g_{i, t^{\prime}}^{a}+g_{i, t^{\prime}}^{b}$

$0 \leq g_{i, t^{\prime}}^{a} \leq\left(\right.$ Pint $\left._{\mathrm{i}}-\operatorname{Pmin}_{i}\right) z_{i, t^{\prime}}$

$0 \leq g_{i, t^{\prime}}^{b} \leq\left(\operatorname{Pmax}_{i}-\right.$ Pint $\left._{i}\right) z_{i, t^{\prime}}$

with $g_{i, t^{\prime}}^{a}$ is the electricity generation between Pmin and Pint of plant $i$ at hour $t^{\prime}$ of the week (MW), $g_{i, t^{\prime}}^{b}$ the electricity generation between Pint and Pmax of plant $i$ at hour $t^{\prime}$ of the week (MW), Pint $_{i}$ the intermediate output of plant $i(\mathrm{MW}), \operatorname{Pmax}_{i}$ the maximum output of plant $i(\mathrm{MW}), \operatorname{Pmin}_{i}$ the minimum output of plant $i$ (MW), $z_{i, t^{\prime}}$ the binary indicating whether plant $i$ is committed or not at hour $t^{\prime}$ of the week: 1 if committed, 0 if not.

The fuel cost function is written as

$C F_{i, t^{\prime}}=c_{i} z_{i, t^{\prime}}+M A_{\mathrm{i}} g_{i, t^{\prime}}^{a}+M B_{i} g_{i, t^{\prime}}^{b}$

with $c_{i}$ is the fuel cost at minimum output of plant $i(€), M A_{i}$ the marginal fuel cost of first load part of plant $i(€ / \mathrm{MWh})$, and $M B_{i}$ the marginal fuel cost of second load part of plant $i(€ / \mathrm{MWh})$.

The start-up cost is modeled as

$C U_{i, t^{\prime}} \geq s_{i}\left(z_{i, t^{\prime}}-z_{i, t^{\prime}-1}\right), \quad C U_{i, t^{\prime}} \geq 0$

with $s_{i}$ : start-up cost of plant $i(€)$.

For the inclusion of minimum up- and downtimes, the following constraints are constructed:

$\forall i \in I, \quad \forall t^{\prime} \in T^{\prime}, \quad \forall k \in\left[1,2, \ldots, m_{i} t_{i}-1\right]$

$\left[z_{i, t^{\prime}}-z_{i, t^{\prime}-1}\right]+\left[z_{i, t^{\prime}+k-1}-z_{i, t^{\prime}+k}\right] \leq 1$

$\forall i \in I, \quad \forall t^{\prime} \in T^{\prime}, \quad \forall k \in\left[1,2, \ldots, m \mathrm{~d} t_{i}-1\right]$

$\left[z_{i, t^{\prime}-1}-z_{i, t^{\prime}}\right]+\left[z_{i, t^{\prime}+k}-z_{i, t^{\prime}+k-1}\right] \leq 1$

with $m d t_{i}$ is the minimum downtime of plant $i(\mathrm{~h}), m u t_{i}$ the minimum uptime of plant $i(\mathrm{~h})$.

The first terms between brackets in (37) and (38) reflect a startup or a shut-down, respectively, the second guarantees that the plant remains on- or off-line during the required number of hours.

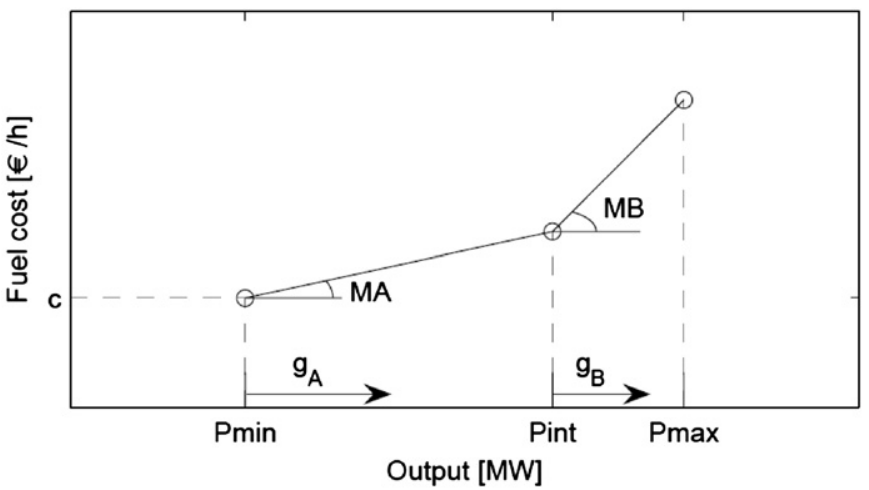

Fig. 12. Stepwise cost function of power plant (Delarue, 2009).

\section{References}

Aditya, S.K., Das, D., 2001. Battery energy storage for load frequency control of an interconnected power system. Electric Power Systems Research 58, 179-185. Belpex, 2010a. Available from:〈http://www.belpex.be〉 (accessed 19.08.10). Belpex, 2010b. Market Resilience Analysis. Available from: < <http://www.belpex. be/uploads/Market_resilience_analysis.pdf $\rangle$ (accessed 19.08.10).

Black, M., Strbac, G., 2006. Value of storage in providing balancing services for electricity generation systems with high wind penetration. Journal of Power Source 162, 949-953.

Delarue, E., 2009. Modeling electricity generation systems. Applied Mechanics and Energy Conversion. University of Leuven (K.U.Leuven), Leuven.

Denholm, P., Sioshansi, R., 2009. The value of compressed air energy storage with wind in transmission-constrained electric power systems. Energy Policy 37, 3149-3158

Dufo-López, R., Bernal-Agustín, J.L., Domínguez-Navarro, J.A., 2009. Generation management using batteries in wind farms: economical and technical analysis for Spain. Energy Policy 37, 126-139.

Electricity Advisory Committee, 2008. Bottling Electricity: Storage as a Strategic Tool for Managing Variability and Capacity Concerns in the Modern Grid. Available from: <http://www.oe.energy.gov/final-energy-storage_12-16-08 pdf $>$ (accessed 19.08.10)

Elia, 2010. Available from:〈http://www.elia.be〉 (accessed 19.08.10).

EPRI, 2007. Market Driven Distributed Energy Storage Requirements for Load Management Applications, 1014668.

EPRI, US Department of Energy, 2003. EPRI-DOE Handbook of Electricity Storage for Transmission and Distribution Applications, 1001834

EPRI, US Department of Energy, 2004. EPRI-DOE Handbook Supplement of Energy Storage for Grid Connected Wind Generation Applications, 1008703.

Kapsali, M, Kaldelli, J.K, 2010. Combining hydro and variable wind power generation by means of pumped-storage under economically viable terms. Applied Energy 87, 3475-3485.

Korpaas, M., Holen, A.T., Hildrum, R., 2003. Operation and sizing of energy storage for wind power plants in a market system. International Journal of Electrical Power and Energy Systems 25, 599-606.

Lund, H., Salgi, G., Elmegaard, B., Andersen, A.N., 2009. Optimal operation strategies of compressed air energy storage (CAES) on electricity spot markets with fluctuating prices. Applied Thermal Engineering 29, 799-806.

Muche, T., 2009. A real option-based simulation model to evaluate investments in pump storage plants. Energy Policy 37, 4851-4862.

Sandia National Laboratories, 2004. Energy Storage Benefits and Market Analysis Handbook, SAND 2004-6177.

Sandia National Laboratories, 2005. Estimating electricity storage power rating and discharge duration for utility transmission and distribution deferral, SAND 2005-7069.

Sandia National Laboratories, 2007. Installation of the first distributed energy storage system (DESS) at American Electric Power (AEP), SAND 2007-3580.

Sioshansi, R., 2010. Welfare impacts of electricity storage and the implications of ownership structure. Energy Journal 31, 173-198.

Sioshansi, R., Denholm, P., Jenkin, T., Weiss, J., 2009. Estimating the value of electricity storage in PJM: arbitrage and some welfare effects. Energy Economics 31, 269-277.

Walawalkar, R., Apt, J., 2008. Market Analysis of Emerging Electric Energy Storage Systems, DOE/NETL-2008/1330.

Walawalkar, R., Apt, J., Mancini, R., 2007. Economics of electric energy storage for energy arbitrage and regulation in New York. Energy Policy 35, 2558-2568. 